\title{
DOCUMENTO
}

\section{Fiebre amarilla}

\author{
COMITE DE INFECCIONES EMERGENTES*
}

YELOW FEVER

La fiebre amarilla es una enfermedad viral transmitida por mosquitos del género Aedes. La forma grave se caracteriza por daño hepático, renal y miocárdico así como hemorragias y tiene alta mortalidad. Está ampliamente distribuida en América Latina, en las zonas correspondientes al Amazonas y en el Africa subsahariana.

Después del brote de fiebre amarilla en Chile en 1912, se logró la erradicación del vector, Aedes aegypti y con ello la enfermedad. Recientemente se detectó la reaparición de este mosquito en Isla de Pascua pero libre del virus. Este hallazgo ha motivado un análisis sobre el tema y la proposición de medidas de prevención.

\section{Agente}

La enfermedad es producida por el virus de fiebre amarilla, ARN, perteneciente a la familia Flaviviridae. Es un virus pequeño de 40 a 60 $\mathrm{nm}$, con envoltura, capaz de replicarse en el citoplasma de las células infectadas. Existe sólo un serotipo que es antigénicamente conservado.

\section{Epidemiología}

En Chile existió fiebre amarilla hasta 1912, importada desde Ecuador, en que se produjeron 1.101 casos con 394 muertes. Se realizó en esa época una exitosa campaña de erradicación del vector sin que se hayan notificado posteriormente casos autóctonos.

Desde 1980 se ha observado la re-emergencia de esta enfermedad en América Latina y Africa con un total de 18.735 casos y 4.522 muertes reportadas entre 1987 y 1991. Los países latinoamericanos que reportan un mayor número de casos son Bolivia, Brasil, Colombia Ecuador, Perú y Venezuela, notificándose desde 19853.012 casos con 1.807 muertes. Perú experimentó en 1995 el brote más grande de los últimos 40 años con 499 casos y 192 muertes.

La OMS ha demostrado por estudios epidemiológicos que existe una gran sub-notificación de los casos estimándose por ajuste alrededor de 200.000 nuevos casos por año, la mayoría de ellos en el Africa Sub-Sahariana.

El ciclo primario de transmisión (selvático) involucra primates y al vector, un mosquito del género Haemagogus en América del Sur y Aedes africanus en Africa. Las personas que

\footnotetext{
* Miembros del Comité de Infecciones Emergentes: Katia Abarca V, Jeannette Dabanch P., Cecilia González C., Leonardo Maggi C., Roberto Olivares C., Cecilia Perret P., Jaime Rodríguez T. y Rodrigo Vergara F.
} 
concurren a las zonas selváticas son las que se exponen al riesgo de adquirir la enfermedad especialmente hombres jóvenes que por su actividad laboral, agricultura o deforestación, tienen mayor probabilidad de enfermar.

El ciclo de transmisión urbano involucra a seres humanos y al vector $A$. aegypti, que crece en acumulaciones de agua dulce y limpia. Prolifera importantemente durante la estación de las lluvias en las zonas tropicales debido al apozamiento de las aguas. En los años recientes este mosquito ha re-invadido América del Sur, desde donde prácticamente había sido erradicado, con reaparición de casos selváticos e incrementando el riesgo de la aparición nuevamente de fiebre amarilla en las zonas urbanas desde donde fuera erradicada varias décadas atrás. La hembra mosquito tiene hábito de alimentación diurna, se infecta al alimentarse de una persona virémica y transmite el virus a otro individuo.

\section{Patogenia}

El Aedes hembra infectado puede inocular durante su alimentación aproximadamente 1.000 partículas virales en el tejido subcutáneo. La replicación viral se inicia en el sitio de la inoculación y se disemina a través de vasos linfáticos a linfonodos regionales donde se replica especialmente en monocitos-macrófagos. Por vía linfática el virus alcanza a otros órganos, incluidos bazo e hígado, donde se replica intensamente produciéndose la viremia y con ella, la siembra a otros tejidos. La fase virémica ocurre entre los días 3 y 6 de iniciada la sintomatología. Durante este período los mosquitos pueden infectarse mientras se alimentan.

La fiebre amarilla grave se caracteriza por insuficiencia hepática, falla renal, coagulopatía y shock. La injuria del hepatocito es caracterizada por una degeneración eosinofílica y en los casos no fatales se produce una recuperación completa sin fibrosis postnecrótica. El daño renal se caracteriza por degeneración eosinófilica y grasa del epitelio tubular, probablemente por daño directo del virus en estas células y también por cambios no específicos secundarios a hipotensión y síndrome hepatorenal. Se han descrito también alteraciones del miocardio. La diatesis hemorrágica se debe a una disminución en la síntesis hepática de los factores dependientes de vitamina $\mathrm{K}$, coagulación intravascular diseminada y a disfunción plaquetaria.

La fase tardía, caracterizada por un colapso circulatorio está mediada probablemente por desregulación en la producción de citokinas como FNT- $\alpha$, IL-1, INF $\gamma$, factor activador de plaquetas y otras.

Los pacientes que fallecen por fiebre amarilla presentan edema cerebral probablemente como resultado de la disfunción microvascular, sin que se haya demostrado la presencia de partículas virales en el encéfalo

\section{Manifestaciones clínicas}

El espectro clínico abarca desde la infección subclínica, la fiebre no específica sin ictericia y hasta la forma grave con riesgo vital.

Luego de que un individuo es picado por un mosquito infectado, y después de un período de incubación de 3 a 6 días, la mayoría de las personas desarrollan la forma leve, caracterizada por fiebre, malestar, cefalea, fotofobia, dolor lumbosacro y de extremidades inferiores, mialgias, anorexia, náuseas, vómitos y mareos. La duración de este cuadro es de 1 a 3 días. Alrededor de $15 \%$ desarrolla la forma grave consistente en dos fases, una aguda de fiebre, cefalea, mialgias, náuseas y vómitos con remisión de los síntomas durante 24 a 48 hrs, seguida de una fase tóxica final caracterizada por retorno de la fiebre, ictericia, epistaxis, hematemesis, melena, oliguria, disfunción hepática, renal, cardiovascular y muerte. Las alteraciones del laboratorio se caracterizan por leucopenia, trombocitopenia, prolongación del tiempo de protrombina, elevación de transaminasas, especialmente aspartato transferasa (AST), hiperbilirrubinemia, aumento de creatininemia y nitrógeno ureico plasmático y proteinuria. El ECG puede mostrar bradicardia sinusal.

El pronóstico se define durante la segunda semana de evolución. 20 a 50\% de los pacientes que desarrollan la forma grave fallecen. La anuria, shock, hipotermia, agitación, convulsio- 
nes, hipoglicemia, hiperkalemia y acidosis metabólica son elementos predictivos de fallecimiento.

La convalecencia puede asociarse a fatigabilidad, ictericia y elevación de las transaminasas persistente y de larga duración.

\section{DIAGNOSTICO}

\section{Diagnóstico clínico}

Definición recomendada para vigilancia y de acuerdo a los criterios de la OPS: Se considera sospechosa de fiebre amarilla a aquella enfermedad de comienzo brusco seguido de ictericia luego de 2 semanas de iniciados los primeros síntomas más uno de los siguientes criterios: a) sangramiento nasal, encías, tracto gastrointestinal o piel. b) muerte en 3 semanas luego de la instalación de la enfermedad.

Estos criterios requieren el antecedente de exposición en zona de riesgo.

\section{Diagnóstico de laboratorio}

\section{Diagnóstico indirecto}

Serología. El diagnóstico se hace mediante la identificación de anticuerpos específicos para fiebre amarilla, IgM e IgG. Se han desarrollado diferentes técnicas de ELISA de captura. La IgM aparece después de la primera semana de iniciado los síntomas y su presencia constituye diagnóstico definitivo de enfermedad. El diagnóstico mediante $\mathrm{IgG}$ requiere del aumento de cuatro veces los títulos en dos muestras de sangre consecutiva, especialmente válido en aquellas personas que viven en zonas endémicas. En Chile bastaría con una muestra positiva para el diagnóstico asociado a síntomas sugerentes, dada la ausencia de la infección en el país. Estos anticuerpos presentan reacción cruzada con otros flavivirus como dengue y encefalitis japonesa.

Otros métodos de diagnóstico serológicos incluyen fijación de complemento, inhibición de la hemoaglutinación y anticuerpos neutralizantes.

En Chile está disponible con fines diagnósticos la técnica de ELISA para IgG e IgM.
(Disponible en ISP y Laboratorio de Virología y Biología Molecular del Centro de Investigaciones Médicas de la Pontificia Universidad Católica).

\section{Diagnóstico directo}

Aislamiento viral. El virus de fiebre amarilla puede ser cultivado en líneas celulares específicas o en cerebro de ratón lactante. Puede ser aislado desde la sangre durante la primera semana de la enfermedad después de la cual disminuye considerablemente la viremia, en coincidencia con la aparición de IgM específica.

Reacción de polimerasa en cadena. Este método de diagnóstico amplifica el genoma viral en sangre y tejidos. Su máximo rendimiento en sangre es durante la primera semana de síntomas, coincidente con una mayor viremia.

\section{Tratamiento}

El tratamiento es sintomático. El manejo de pacientes graves debe realizarse en unidades de cuidados intensivos con monitoreo estricto y medidas de apoyo general que incluyen aporte de fluidos, fármacos vasoactivos, oxígeno, prevención de hipoglicemia, corrección de acidosis metabólica, manejo de la coagulopatía y soporte renal.

No existe tratamiento antiviral específico disponible. La ribavirina se ha demostrado eficaz in vitro en altas concentraciones que son incompatibles con su utilización clínica. Otros antivirales se han estudiado pero su aplicación en humanos ha sido limitada por toxicidad.

\section{Prevención}

Protección contra picadura de mosquito. En países endémicos el vector se encuentra en áreas urbanas dentro y fuera de las viviendas. Para personas que viajan a zonas endémicas se sugiere el uso de insecticidas como permetrina en la ropa, cuyo efecto es de larga duración resistiendo 4 a 5 lavados y repelentes de uso tópico que contengan DEET en concentraciones entre 30 a $35 \%$. Este tipo de repelente no se encuentra actualmente en Chile por lo que se recomienda su adquisición en los países de 


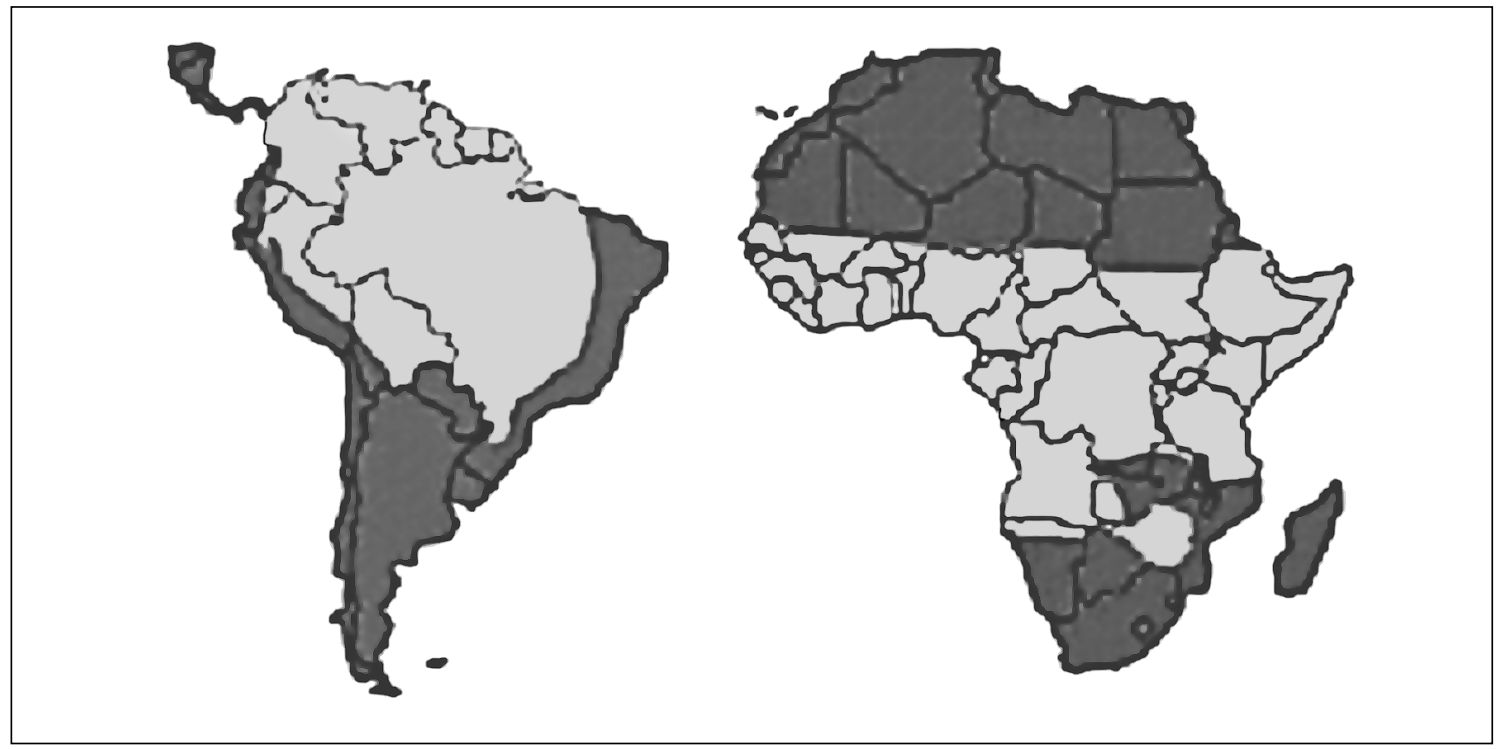

Figura 1. Distribución de fiebre amarilla en el mundo en 1996. Las regiones demarcadas en gris corresponden a zonas endémicas.

destino. Debe ser aplicado en la piel expuesta con la precaución de evitar contacto con conjuntiva y otras mucosas debido a su toxicidad. En niños se recomiendan concentraciones no mayores de $30 \%$. Los perfumes atraen a los mosquitos por lo que al evitar su uso se contribuye a prevenir las picaduras. El uso de aire acondicionado controla la circulación del mosquito.

Inmunización activa. La vacunación es el método más práctico y seguro para prevenir la fiebre amarilla en personas con riesgo. La vacuna 17D (Stamaril® de Aventis Pasteur) es una de las vacunas atenuadas de mayor éxito que se hayan desarrollado, es inmunogénica y altamente protectora. Una dosis de $0,5 \mathrm{ml}$ induce una inmunidad duradera en más del $95 \%$ de los casos a partir del décimo día de su aplicación y es aceptada internacionalmente como prevención de enfermedad por un período de 10 años (certificación internacional) aunque probablemente deje inmunidad de por vida. Rara vez se observan reacciones adversas serias siendo lo más frecuente fiebre moderada, decaimiento y dolor en el sitio de inoculación. Estos síntomas aparecen entre 5 y 10 días después de la vacunación.

Se recomienda a toda persona mayor de 9 meses de edad que viaja a zonas donde existe el riesgo de transmisión de la enfermedad o a aquellas provenientes de zonas endémicas que ingresan a países donde existe el vector, según la normativa de regulación internacional de salud de la OMS.

Está contraindicada en mujeres embarazadas y en lactantes bajo 9 meses de edad a menos que el riesgo de contagio sea muy elevado. En lactantes bajo de 4 meses de vida está formalmente contraindicada la inmunización debido al riesgo de encefalitis secundaria. La vacuna es elaborada en embriones de pollo por lo que las personas alérgicas al huevo deben realizarse un test cutáneo previo a la vacunación.

Los pacientes portadores de VIH asintomáticos pueden ser inmunizados aunque su respuesta inmune puede ser menor.

Esta vacuna puede ser administrada en conjunto con vacuna oral o parenteral para fiebre tifoidea, hepatitis A y B, sarampión, polio y vacuna anti meningocóccica. La administración conjunta a otra vacuna con virus vivo atenuado idealmente debe ser simultánea. Si esto no es posible se recomienda un intervalo de al menos 30 días para evitar interferencia en la respuesta inmune. La vacuna del cólera debe 
ser aplicada al menos con 3 semanas de intervalo.

Esta vacuna está disponible actualmente en Chile en el Vacunatorio Internacional de la Región Metropolitana y en algunos otros vacunatorios del Sistema de Salud a lo largo de Chile.

Dada la aparición del vector en el territorio nacional, Isla de Pascua, se hace planteable la necesidad de revisar las normas de inmunización internacional de fiebre amarilla para evitar la aparición de la enfermedad, así como la mantención de la vigilancia entomológica y de casos de fiebre amarilla en humanos, lo que actualmente se realiza.

\section{BIBLIOGRAFIA}

1. MONATH T. Yellow Fever. UpTo Date 2000; 8 (1)

2. PAHO. Yellow Fever. Case definition. Epidemiol Bull 2000; vol $21 \mathrm{~N}^{\circ} 1$.

3. ROBERTSON S, HULL B, TOMORI O, BELE O et al. Yellow Fever. A decade of reemergence. JAMA 1996; 276: 1157-62.

4. PAHO. Update on Yellow Fever in the Americas. Epidemiological Bull Aug 2000; Vol $21 \mathrm{~N}^{\circ} 2$.

5. MONATH T, GIESBERG J, GARCIA FIERROS E. Does restricted limit access and coverage of yellow fever vaccine in the United Staes? Emerg Infect Dis 1998; 4: (4): 698-702.

6. Yellow fever vaccine. Infect Med, 2000; 17: 168-71.

7. OLEA A. Historia de las enfermedades infecciosas en Chile. El Vigía 2000; 3: 5-6. 